\title{
REVIEWS
}

CHRONIC PULMONARY DISEASE IN SOUTH WALES COALMINERS. III.-EXPERIMENTAL STUDIES

Medical Research Council, Special Report Series, No. 250

(H.M. Stationery Office, London. 1945. Pp. 94. 5s.)

Nos. 243 (1942) and 244 (1943) of the Special Report Series were devoted to the study of chronic pulmonary disease in South Wales coalminers; the first was a clinical and pathological study, and the second an environmental study. The present report is a sequel to these and is concerned with experimental studies. It is the greatest contribution to our understanding of silicosis yet made. Broadly there are three sections: the first a study of the mineral content of the lungs of some 54 miners by King and Nagelschmidt, the second an investigation into the tissue reactions in the lungs of rats caused by selected dusts from the South Wales coalmines by Belt and King, and the third a study of the solubility of the dusts by King.

The lungs of the 54 workers in the coal-field were analysed chemically for silica, alumina, and coal; and the quartz, mica (sericite) and kaolin were determined by $\mathrm{x}$-ray diffraction-pattern analysis in the minerals contained in the lungs which were isolated as residues. The results of these studies showed that the composition of the dust in the lung reflected the nature of the man's employment, and was identical with the dust to which he had been exposed at work. The pathological lesions in the lungs showed no relation with either the coal or kaolin in the dust; but the concentrations of mica and quartz ran more or less parallel with the degree of fibrosis observed.

Pure or 'clean' coal, that is mineral that contains more than 90 per cent. coal, whether it is anthracite, bituminous or steam coal, produced in animals nothing more than the simplest type of foreign body reaction with mineral fibrosis. There was some concomitant emphysema and decreased vital capacity, and the animals lived six months less than controls. The histological picture was similar to the dust reticulation of coalminers. On the other hand, coal dusts with a siliceous content of more than $12 \frac{1}{2}$ per cent. produced a reticulation fibrosis, a type of organization similar to carnification. Mica and kaolin were often present and the amount of quartz was small, thus there is evidence that some silicates may be fibrogenic, though on the other hand the silicates comprising clod strata (shale) appeared to inhibit the fibrogenic properties of quartz. Specimens of pure mica (sericite) from South Wales produced an absolute minimum of reticular fibrosis whereas a sample of mica (hydromuscovite or sericite) from another source used as a control, produced heavy nodular reticulin fibrosis similar to quartz.

The incidence of acute inflammatory reaction to a dust was closely parallel with the higher grades of fibrogenesis. The initial impact of silica is on the phagocyte, and it is not until this is disintegrated that it falls on the connective tissue. The most severe reactions undoubtedly result from quartz, but the pathogenicity of this substance is reduced by clean coal and practically abolished by shale. The result is dependent evidently on an interplay of adjuvant and antidotal factors, the adjuvant effect of tubercle in human silicosis and the antidotal effect of aluminium are known, but there are probably many others which still remain unknown.

There is little doubt that the production of silicosis depends on the solubility of silica. It is proved that quartz particles coated with iron-oxide or alumina are less soluble and less harmful than those which are not. It is surprising, therefore, to find that all South Wales dusts show low silica solubilities. Shales depressed the solubility apparently by releasing aluminium from their aluminous components to form a protective covering which could be stained with aurine, over the quartz particles; this effect, however, was not related to the total aluminium content of the sample. One of the most perplexing findings, however, is that anthracite coals depressed the silica solubility of quartz markedly, whereas steam and bituminous coals did so very much less; yet severe pneumokoniosis has a much higher incidence in anthracite workers. King suggests as an explanation that in some way bituminous and steam coal inhibit the solubility of the siliceous matter contained therein, whereas anthracite has not this property of combination (the content of siliceous matter is the same in all three), and so its mineral content can produce its effect, either under experimental conditions by inhibiting the solution of added quartz, or under conditions in the mine by not preventing the solution of siliceous material as other coals do.

K. M. A. P.

\section{LE TRAITEMENT DES ACCIDENTS DU TRAVAIL MANUEL DU PRACTICIEN}

By J. Boudreaux, A. Hanuat and M. Iselin (with the help of Ch. Duvelleroy)

(Foundation Francaise pour l'etude des Problemes Humains. Librairie de Medicis, Paris. 1945. Pp. 163. Fr. 81)

This work gives an account of the treatment of minor industrial accidents which are defined as those which can be dealt with satisfactorily without the help of general anaesthesia. The ground covered is therefore fairly wide, although not everyone would agree that conditions such as fracture of the scaphoid and distal end of the radius should be treated in this manner. The book is primarily intended for the French general practitionersurgeon who undertakes minor traumatic surgery, and the introduction gives in some detail the organization of a service of this kind not only describing the layout of the buildings required but also indicating the duties of the nursing staff as well as giving a note on the necessary materials and instruments. Stress is rightly laid on the devotion of adequate time by the operator to the procedures described and it appears that the ill-results which follow work done in haste by poorly trained surgeons in indifferently equipped surroundings are to be met with in France as well as on this side of the Channel.

The main part of the book is, like Gaul, divided into three parts which deal respectively with what are called 'closed injuries' (contusions, sprains, dislocations, fractures and lumbago of traumatic origin), 'wounds,' and 'specialties.' Under the last named are chapters by appropriate specialists on ophthalmology, oto-rhinolaryngology and stomatology. There is a short appendix on the emergency treatment of accidents.

The text is written in clear simple language and in general follows modern practice, but it is an indication of the scientific isolation in which France has found herself until recently that a book published in 1945 should have no mention of the use of penicillin. Noteworthy also is the absence of reference to the rehabilitation of the injured workman and the important part played by the industrial medical officer in this phase of treatment. Our French colleagues seem to have something to learn from us about this. The book has a good table of contents but lacks an index.

\section{MEMORANDUM ON CARBON MONOXIDE POISONING}

Factory Dept., Ministry of Labour and National Service

(H.M. Stationery Offlce, London. 1945. Pp. 32. 6d.)

So much has been written in the technical and physiological literature on the effects of carbon monoxide on man and animals, on blood in vitro and in vivo, and on tissue respiration that it would almost seem superfluous to issue further information on the subject. But it will be apparent to all who have to do with industrial acci- 